\title{
Exploring a pathway towards energy conservation through emphasizing the connections between energy, systems, and fields
}

\author{
Marcus Kubsch $^{1 *}$ D, Sebastian Opitz ${ }^{2^{*}}$, Jeffrey Nordine ${ }^{1}$, Knut Neumann ${ }^{1}$, David Fortus ${ }^{3}$ and Joseph Krajcik ${ }^{4}$
}

\begin{abstract}
Energy conservation is a fundamental concept in physics and across the sciences as it provides a lens for investigating a wide range of phenomena. Research into energy learning progressions has shown that a majority of students across K-12 struggle with energy conservation. These studies characterize students' learning progressions as starting from energy being manifest in different forms. Research suggests that learning progressions that begin with the idea of forms only lead to an understanding of conservation for a minority of students. Thus, the question arises whether there are alternative, more productive pathways towards conservation than going through forms. We investigated to what extent students progress towards conservation if they are taught in a transfer-only approach to teaching energy that does not require forms. Drawing on interviews from $N=30$ students across different time points in a 10 week transfer-only unit, we found that at the end of the unit, most students tracked energy successfully across systems, and did not violate energy conservations when explaining phenomena, that is, progressed towards a qualitative understanding of conservation. Our results imply that energy learning progressions do not have to go through forms and in fact a more productive pathway towards conservation may exist in the transfer-only approach.
\end{abstract}

Keywords: Energy, Conservation, Fields, Middle school, Learning progressions, Substance metaphor

\section{Introduction}

Energy is a fundamental concept in physics and across the sciences as it provides a lens for investigating and analyzing a wide range of phenomena. At the core of the energy concept lies the idea of energy conservation which helps determine to what extent one has accounted for the relevant systems and changes in those systems in a model or explanation of a phenomenon.

In the Framework for K-12 Science Education (National Research Council, 2012) and the US Next

\footnotetext{
* Correspondence: kubsch@leibniz-ipn.de; opitz@leibniz-ipn.de

'Department of Physics Education, Leibniz-Institute for Science and

Mathematics Education (IPN), Kiel, Germany

${ }^{2}$ Department of Biology Education, Leibniz-Institute for Science and

Mathematics Education (IPN), Kiel, Germany

Full list of author information is available at the end of the article
}

Generation Science Standards (NGSS Lead States, 2013), energy is both a disciplinary core idea and a crosscutting concept, emphasizing that energy is not only important in physics but also fundamentally important in biology, chemistry, and earth science. In biology, energy determines for example which organisms can make best use of limited energy resources in order to produce competitive offspring, in chemistry, energy helps determine which reactions can occur and which cannot, and in earth science, energy is a critical concept to model how Earth's systems interact. The learning progression outlined in the Framework for K-12 Science Education suggests that at the end of grade 5 , students have started recognizing manifestations of energy in nature and know that energy can move from place to place through 
various processes. By the end of grade 8 , students are supposed to have developed a more thorough understanding of how energy is manifest in nature and that it can be either stored in the movement of objects or fields. Further, they should recognize that whenever the energy of one system changes, there is a corresponding change of energy in some other systems. This statement reflects a qualitative understanding of energy conservation (see also Gray, Wittmann, Vokos, \& Scherr, 2019). By the end of grade 12, students are supposed to have further refined those ideas and developed the necessary mathematics to apply ideas about the manifestations of energy, energy transfer, and energy conservation quantitatively.

However, research into the energy learning progression has time and again shown that a majority of students across K-12 and across the sciences struggle with the idea of energy conservation (Herrmann-Abell \& DeBoer, 2017; Liu \& McKeough, 2005; Neumann, Viering, Boone, \& Fischer, 2013; Park \& Liu, 2016). A common feature of all these studies is that they characterize students' learning progressions as starting from the idea of energy being manifest in different forms or from precursors of this idea. It appears as if learning progressions that begin with the idea of forms only lead to an understanding of conservation for a minority of students. Thus, the question arises whether there are alternative, more productive pathways towards conservation than going through forms.

Numerous scholars have proposed approaches that do not require forms of energy but emphasize transfers of energy between systems (Brewe, 2011; Ellse, 1988; Falk, Herrmann, \& Schmid, 1983; Lehavi, Eylon, Hazan, Bamberger, \& Weizman, 2012; Nordine et al., 2018; Swackhamer, 2005). However, for such an approach to work consistently without introducing forms at some point, the concept of fields is required (Swackhamer, 2005). Although it may seem ambitious to introduce three complex ideas - energy, systems, and fields - in introductory energy instruction, ideas about systems and fields are integral to the energy concept (Coopersmith, 2015) and the recommendations in the Framework for K-12 Science Education (National Research Council, 2012) and the US Next Generation Science Standards (NGSS Lead States, 2013) align with this proposal.

In this paper, we investigate to what extent middle school students in a unit that emphasizes energy transfer and excludes the idea of energy forms progress towards an understanding of conservation and how students in such a unit use fields and energy ideas in conjunction in order to explain phenomena.

\section{Theoretical background}

Energy ideas are useful in order to explain phenomena because energy is conserved, i.e., the amount of energy in a system can only change due to transfers of energy into or out of that system. Being a conserved quantity turns energy into a powerful analytical lens to support reasoning about phenomena: It allows to find out whether an explanation or model of a phenomenon accounts for all relevant changes and systems that interact in the phenomenon. A famous example of this is the discovery of the Neutrino by Wolfgang Pauli who predicted the Neutrino in response to apparently missing energy in beta-decay spectra (Guerra, Leone, \& Robotti, 2014).

\section{Teaching and learning about energy}

A well corroborated finding of the research into the teaching and learning of energy is that only few students develop an understanding of energy conservation. Research into energy learning progressions regularly identifies energy forms or manifestations of energy as the lowest level and energy conservation as the highest (Herrmann-Abell \& DeBoer, 2017; Liu \& McKeough, 2005; Neumann et al., 2013). A caveat of these studies is that they are cross-sectional and lack an instructional component. In contrast, Nordine, Krajcik, and Fortus (2011) studied students learning in a unit focusing on the central idea of transformations of energy forms. While students made progress in developing a more integrated understanding of energy, they still struggled with the idea of energy conservation. Similarly, Bächtold and Munier (2018) who studied students' learning in a unit inspired by the history and philosophy of science found that only few students progressed from an understanding of energy forms to mastery of conservation ideas. Lastly, Neumann and Nagy (2013) tracked students' progress from grade 6 to 10 in an observational study, i.e., without an instructional component. Their results suggest that students generally progress from forms through transformations and dissipation towards conservation but rarely master it.

It is not only well documented that students struggle with conservation but also how they struggle with conservation: students may consider individual forms of energy to be conserved (Nordine et al., 2011) or struggle to conceptualize individual forms (Falk et al., 1983; Hecht, 2003; Kaper \& Goedhart, 2002a; Quinn, 2014), students may consider the energy of any system to be conserved, regardless of the changes that the system undergoes (Lindsey, Heron, \& Shaffer, 2012) or students think that energy is not conserved in dissipative phenomena (Daane, Haglund, Robertson, Close, \& Scherr, 2018; Solomon, 1985; Tobin et al., 2012, 2019). Dissipative phenomena invite the notion that energy is not conserved because, in such phenomena, it appears as if energy disappears: when a falling ball hits the ground or a pendulum in air eventually stops swinging, it is not obvious where the energy has gone as the respective energy 
transfers out of the systems of interest such as the ball or pendulum are hardly, if at all, perceptible. As everyday experiences overwhelmingly reflect dissipative phenomena, it is not surprising that students struggle to adhere to energy conservation when explaining such phenomena (Chabalengula, Sanders, \& Mumba, 2012).

\section{A transfer-focused pathway towards conservation}

Based on proposals in the literature to emphasize energy transfer (Brewe, 2011; Ellse, 1988; Swackhamer, 2005), the recommendations in the US Next Generation Science Standards (NGSS Lead States, 2013) and the Framework for K-12 Science Education (National Research Council, 2012), Nordine et al. (2018) have proposed a new approach to introductory energy instruction that leads students to explain phenomena from an energy perspective - but without introducing energy forms.

This transfer-only approach focuses on transfers of energy between systems and emphasizes different aspects of the idea of energy conservation compared to traditional forms-based approaches. In a forms-based approach, energy conservation is a primarily quantitative concept that emphasizes that the sum of all involved forms of energy remains equal (Gray et al., 2019). The transfer-only approach, however, reflects a qualitative notion of conservation: it emphasizes that energy always has to be in some system, i.e., when the energy of a system changes, there has to be another change in energy in some other system. In sum, conservation in a formsbased approach emphasizes how energy can work as an accounting tool (Feynman, 1965), something that ultimately becomes useful when setting up equations to describe phenomena. In contrast, conservation in a transfer-only approach emphasizes how energy, similar to matter, is always localized, i.e., has to be tied to a physical system (Quinn, 2014).

Emphasizing the qualitative notion of energy conservation can help turn energy into a powerful lens allowing reasoning about phenomena. When students acknowledge that energy always has to be in some system, this naturally leads to questions like "Where is the energy coming from?" or "Where is the energy going to?" when facing a new phenomenon. These questions implicitly acknowledge that energy is conserved (Tobin et al., 2019) and attempting to answer these questions can lead to deep insight as the example of the Neutrino demonstrated.

The implicit notion of energy conservation in a question like "Where is the energy going to?" can support students in using energy ideas in dissipative phenomena. In such phenomena, it is often not obvious where energy is being transferred to. Daane, McKagan, Vokos, and Scherr (2015) and Tobin, Lacy, Crissman, and Haddad (2018); Tobin et al. (2019), however, provide evidence from multiple vignettes that emphasize transfers of energy between systems and provide a framework of related questions like "Where is the energy going?". It supports students in using energy in order to reason about the systems and changes therein in dissipative phenomena, e.g., an increase in temperature in the spot of the floor where a falling ball hit it. Thus, the transferonly approach may support students in applying conservation ideas productively (see Tobin et al., 2019), meaning that they consider aspects of phenomena that would not have been considered without applying energy ideas.

Another class of phenomena where the involved systems and processes are not obvious are those that involve interactions-at-a-distance such as a falling ball attracted by the force of gravity. To discuss such phenomena in a transfer-only approach, the concept of fields needs to be introduced as energy must always be associated with some system. In the example of the falling ball, energy is transferred from the gravitational field between the ball and the earth to the ball. This description aligns with the Framework for K-12 Science Education which states that "Energy $[\ldots]$ can be modeled as either motions of particles or as stored in fields" (National Research Council, 2012 p. 124).

\section{Fields}

Many studies suggest that learning about fields is challenging for students (Bradamante \& Viennot, 2007; Furio \& Guisasola, 1998). However, fields are typically introduced as mathematical abstractions in the context of forces (see e.g., Halliday, Resnick, \& Walker, 2005) and usually reserved for older students (Herrmann, 1989; Hobson, 2013). In contrast, the transfer-only approach introduces fields in the context of energy and presents them as entities that energy can be transferred to or from. Treating fields as any other system and not just a mathematical representation is consistent with modern physics (Furio \& Guisasola, 1998; Herrmann, 1989; Hobson, 2013) and, more generally, may be considered a major goal in developing an understanding of fields (Furio \& Guisasola, 1998; Herrmann, 1989).

In the transfer-only approach, two ideas about fields are required: 1) fields are entities that mediate interactions-at-a-distance and 2) energy can be transferred to and from fields. Interactions-at-a-distance may either occur between macroscopic objects or atomic scale objects. Examples of interactions-at-a-distance between macroscopic objects are magnets attracting or repelling each other or freely falling objects on Earth. Examples of interactions at-a-distance between atomic scale objects explain how energy can be transferred from a trampoline to a person or from a bow to an arrow, i.e., phenomena that involve elasticity. Consider, for example, a bow being bent. At the atomic level, the 
particles that make up the bow change in relative position. This results in a transfer of energy from the person bending the bow to the field between those particles.

Including these fields ideas may support students using energy ideas in phenomena that include interactions-at-a-distance. In traditional forms-based instruction, potential energy is required in order to discuss such phenomena, e.g., in a falling ball, potential energy is transformed into kinetic energy. However, students are often confused about the location of potential energy, i.e., the system to associate potential energy with, and wrongly associate potential energy with single objets which in turn may lead to difficulties in learning about energy more generally (Doménech et al., 2007; Lindsey et al., 2012). Similarly, students sometimes question whether potential energy is real (Hecht, 2003), thus likely leading to difficulties in progressing towards conservation. Fields - when considered as existing, physical entities - provide such location for energy that is not manifest in single objects (Quinn, 2014) and may help students acknowledge that potential energy is real. However, including fields may also be a source of additional difficulty as students may also develop new nonnormative ideas about both, fields and energy, when those two ideas are introduced together. Further, if students do not develop at least some understanding of fields, they will struggle with using energy ideas in order to explain and interpret phenomena that involve interactions-at-a-distance.

\section{Research questions}

In order to investigate to what extent the transfer-only approach provides a feasible alternative way to approaching energy conservation, we asked the following research questions:

1. To what extent do 7 th grade students progress towards an understanding of conservation and apply it over the course of a transfer-only unit?

2. How do students use fields and energy ideas in conjunction in order to explain everyday, physics related phenomena?

\section{Methods}

In this section, we will first provide an overview of the overall design, instruments, and sample. Next, we will describe the transfer-only unit and data sources in more detail. Finally, we will describe how we analyzed the numerous data sources to answer our research questions.

\section{Design and instruments}

Figure 1 gives an overview of the overall design and assessments used in this study. For more details on the assessments and examples see Fortus et al. (2019). Our study is situated in a design-based research and development project. In consequence, the curriculum was enacted multiple times, allowing for data driven revisions between enactments. Depending on the focus of the enactment, different data was collected. Students in our study participated in an approximately 10-week transfer-only energy unit that fell into four-lesson sets which we describe below. Students took open-ended, standard-based energy assessments directly before and after the unit. In addition, we conducted interviews with selected students before and after the unit, as well as two interviews during the unit. The interviews required students to explain both known and unknown phenomena, thus allowing us to see how students' ability to apply conceptual energy understanding from the energy unit progressed throughout the teaching sequence.

\section{Unit enactment and sample}

We draw on data from an enactment of the transferonly energy unit that was carried out in 2017. The unit consists of four-lesson sets of roughly equal length. The unit was designed as a replacement for the 7th grade energy unit in the INVESTIGATE ${ }^{1}$ curriculum (Fortus et al., 2012) that the participating schools employ. Therefore, all students entered the study after similar curricular experiences and in the first half of 7 th grade. The unit was taught in a midwestern, rural school to 181 students ( $53 \%$ male, $47 \%$ female) in 2017 by two experienced teachers. The teachers received 4 days of professional training concerning the transfer-only approach before/during each enactment. Since the teachers were familiar with project-based pedagogy and the curriculum in general, professional development focused mostly on the conceptual differences between traditional formsbased energy instruction and the transfer-only approach as well as the issue of fields. In addition, researchers provided continuous support during the enactments, for example providing teachers with required materials or discussing questions that surfaced during the enactments. Videotaped classroom observations indicate that teachers generally adapted the unit with high fidelity. A more detailed account of how teachers experienced teaching the transfer-only unit is presented in Touitou et al. (2018).

\section{The transfer-only unit}

In this section, we provide a summary of the transferonly unit as it was taught. For more details see Nordine, Fortus, Lehavi, Neumann, and Krajcik (2018).

The unit was designed as a replacement for the 7th grade energy unit in the INVESTIGATE curriculum (Krajcik, Reiser, Sutherland, \& Fortus, 2012) that the

\footnotetext{
${ }^{1}$ INVESTIGATE is a Pseudonym
} 


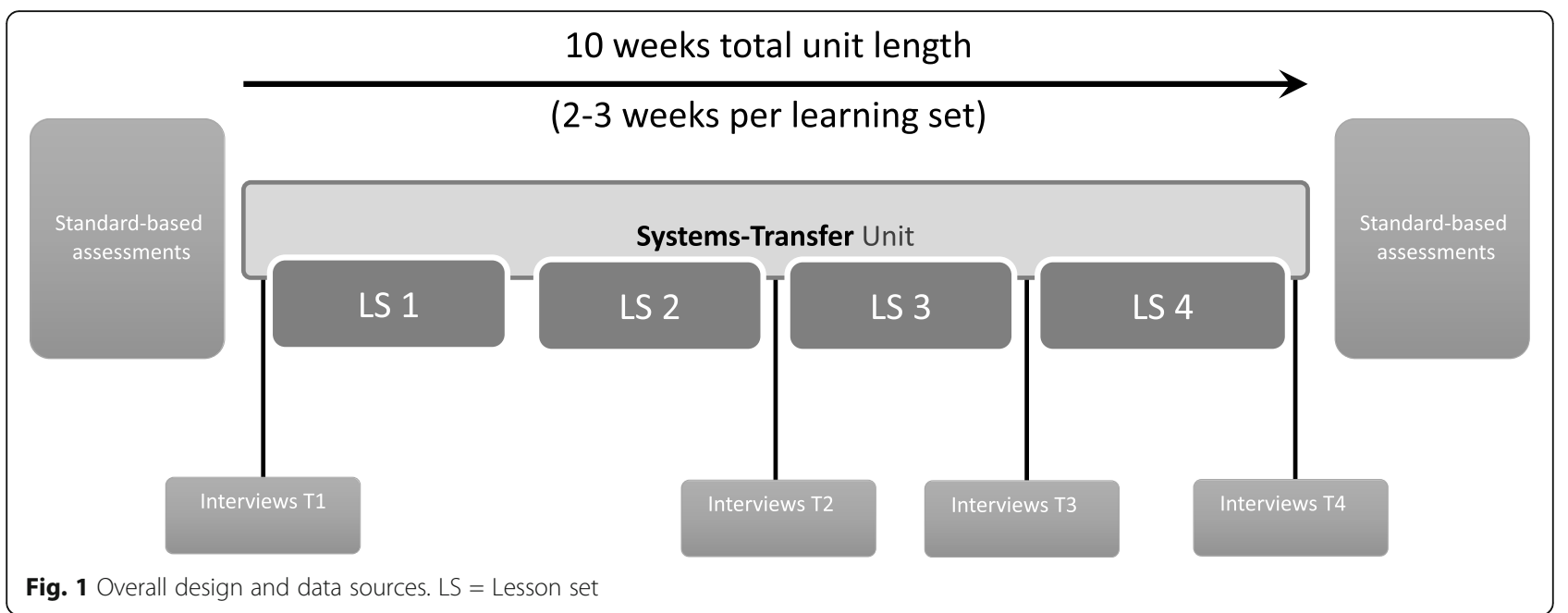

participating schools had adopted. The unit follows project-based pedagogy (Krajcik \& Shin, 2014). In line with this framework, we conceptualize learning as students building increasingly well integrated knowledge around core ideas of the unit (Bransford, 2000; Clark \& Linn, 2013; Linn, 2006). This should be evidenced by students activating and connecting increasingly focused sets of ideas around fields, energy, and systems in order to make sense of phenomena as the unit progresses. To achieve this, the unit is designed to build up students' knowledge systematically and coherently over time, e.g., through a unit-level driving question which is regularly revisited as the unit progresses: "Why do some things stop and others keep going?". Further, the unit was designed to allow three-dimensional learning by integrating scientific practices, disciplinary core ideas, and crosscutting concepts (NGSS, 2013). Lastly, our overarching design principle in addressing the complexities of energy, systems, and fields was to only introduce the absolutely necessary ideas and design the curriculum in such a way that new ideas answer a need-to-know.

While the unit generally focuses on the vision of three-dimensional learning across all scientific practices, the systems-transfer unit emphasizes the practice of modeling by engaging students in a representation called Energy Transfer Model (ETM, see Fig. 2 for an example). Students construct ETMs throughout the unit in order to interpret and explain increasingly complex phenomena. Despite the increase in complexity, the ETMs always encompass three main components: The systems between which energy is transferred (solid-line boxes), the energy transfer (arrows between systems), as well as the occurring processes (both observable and nonobservable; square brackets).

The unit develops the ideas of energy, systems, and fields across four learning sets during which these ideas are used for interpreting increasingly complex phenomena. The following summarizes key ideas and activities in the learning sets. Details about the contents of each set are described in Nordine et al. (2018). The full educational materials will be made available as open educational resources.

\section{LS 1: modeling interactions between systems}

In this learning set, students learn that every phenomenon involves at least two interacting systems that each undergo some process. In line with the Framework for K-12 Science Education (National Research Council, 2012), systems are effectively defined as the relevant parts of the world under study. Students use a simplified version of an ETM to construct and refine simple models of phenomena that represent the interacting systems, how the systems interact, and the processes

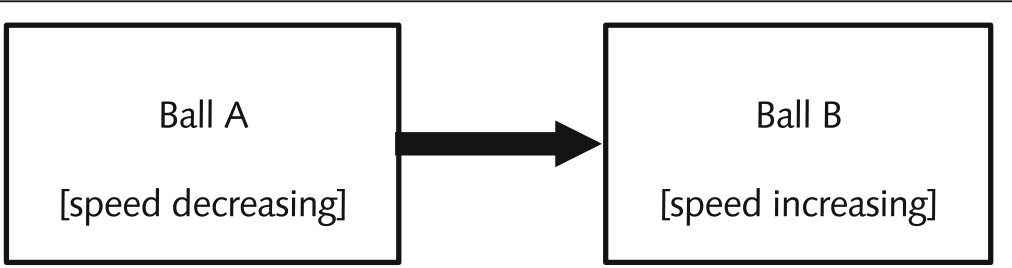

Fig. 2 ETM fort wo balls A and B colliding. The boxes represent the systems, the arrow represents the direction of energy transfer, and the text in brackets describes the energy-related processes in the systems 
that occur in the interacting systems, e.g., students developed models of a radiometer or a Hero's engine.

\section{LS 2: modeling balanced processes}

Here, students take a closer look at the processes in the interacting systems and learn how to connect them to changes in energy and, subsequently, energy transfers between systems. Thus, the definition of systems is slightly extended to emphasize that energy can be transferred to or from systems. A series of investigations allows students to recognize that, anytime energy is transferred to/from one system, it must have been transferred from/to another system that undergoes an opposite energy change. Thus, a first implicit notion of energy conservation is introduced. At the end of learning set 2, students should be able to represent the interacting systems, processes, and energy transfers in various phenomena such as in Fig. 2 using the ETM. Phenomena covered include colliding carts or melting of ice.

In sum, Learning Sets 1 and 2 serve to develop a substance-like model of energy, emphasizing that energy is localized in a system and always has to go or to come from somewhere, i.e., is never created or destroyed which reflects a qualitative notion of energy conservation.

\section{LS 3: energy transfers to and from fields}

This learning set introduces the idea of energy transfers to and from fields in order to interpret phenomena that involve interactions-at-a-distance, such as gravitational and magnetic interactions. In an investigation using iron fillings or a ferro fluid, students learn that the magnetic field changes its shape when magnets interact at a distance. The investigation establishes that objects interact at a distance via fields and that the shape of those fields changes as the distance between the object changes. To establish the connection between fields and energy, two magnetic carts are held together and then released. Students then model this phenomenon using an ETM. They quickly realize that they miss a system that transfers energy to the carts as they speed up. The magnetic field addresses students' need to know what the missing system is and where the energy is coming from. This episode is not only an example of how energy is presented as a useful idea that helps gaining new insight into phenomena in the systems-transfer unit, but also shows how fields are introduced in a substantially different way compared to traditional instruction: Fields are not introduced as a mathematical abstraction, but as a concept that fills a conceptual void. In their ETMs, students represent fields as boxes like any other system (Fig. 3).

Phenomena that students covered include e.g., a pendulum, a bouncing ball, or repelling magnets.

\section{LS 4: modeling complex phenomena and continuing processes}

The last learning set explores energy transfers in more complex phenomena that include continuing processes. Students learn how to extend the Energy Transfer Model to account for relative rates of energy transfer (e.g., in a pendulum that dissipates some of its energy to the surroundings while getting slower). In their ETMs, students mark these differences via varying arrow width (see Fig. 4). This allows students to go back to the driving question and explain that some things keep going as there are balanced energy transfers into and out of the observed system (e.g., electricity being supplied at the same rate to the system of an ideal pendulum as heat is being dissipated from the system to the surroundings) and things stop because energy is dissipated out of the system of interest into the environment.

In this last learning set, phenomena that students model include objects rolling and sliding down a ramp and a battery-powered pendulum.

\section{Instruments}

\section{Standard-based assessments}

To assess students' understanding of energy, we used the same instrument as Fortus et al. (2019) as a pre- and post-test. The assessments were developed following a refined version of the procedure by Harris, Krajcik, Pellegrino, and McElhaney (2016) that synthesizes evidence-centered design (Mislevy \& Haertel, 2007) and construct-mapping (Wilson, 2005). The resulting standard-based, open-ended tasks are aligned with energy related performance expectations for the middle school level in the Next Generation Science Standard. The tasks require students to blend disciplinary knowledge, science practices, and cross-cutting concepts in order to make

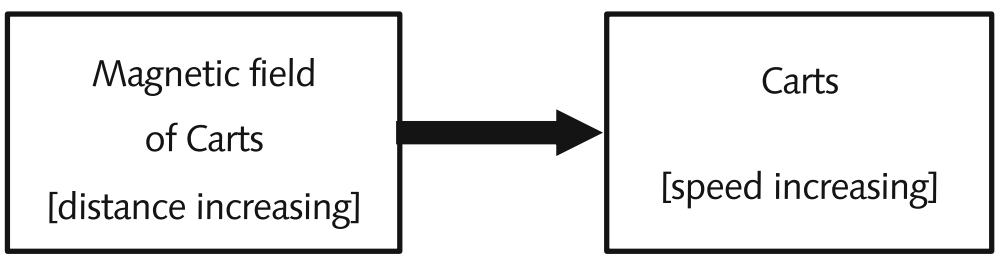

Fig. 3 ETM for two repelling magnetic carts that are held together and then released 


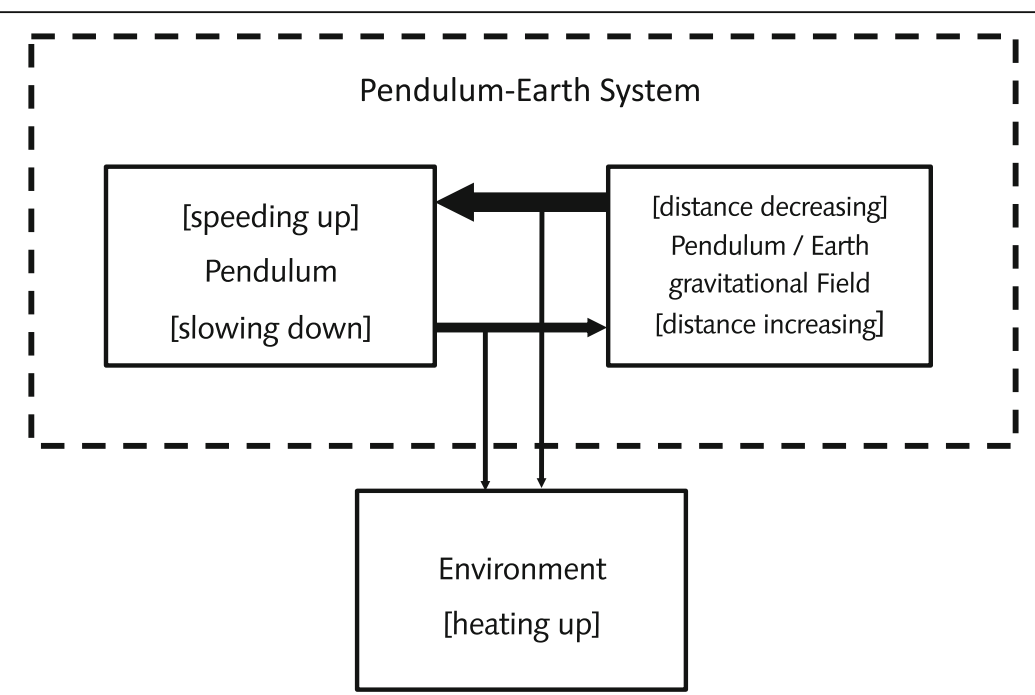

Fig. 4 ETM for a pendulum swinging in air. Arrow thickness represents relative rates of energy flow

sense of real-world phenomena. The goal of the tasks, therefore, is not simply to measure knowledge, but knowledge-in-use (Harris et al., 2016). All tasks were reviewed by external experts for alignment with the learning set learning goals, appropriateness of the context, appropriateness of wording, and whether the task required any additional knowledge. For more details and psychometric properties see Fortus et al., 2019. The tasks and scoring rubric are available in online supplement S1.

The tasks were scored by experienced scorers who were trained by the researchers following a rubric that emphasized the integration of scientific practices and disciplinary knowledge. Depending on the task, students could score up to a maximum of four or six credits. Higher scores reflect a better integration of the scientific practice in the task (e.g., modeling or constructing a scientific explanation) with the relevant disciplinary core idea about energy (e.g., When the kinetic energy of an object changes, there is inevitably some other change in energy at the same time. MS-PS3.B). All student responses were mixed so that scorers could not tell to which measurement timepoint the student answer belonged. $10 \%$ of the student answers were scored by a second rater. We found satisfactory interrater agreement (mean $=84 \%, \mathrm{SD}=10 \%$ ). We focus our analysis on the six identical tasks that were administered in 2017 and 2018. The tasks had satisfactory reliability (Cohen's alpha $=0.74,95 \%$ CI $[0.72,0.76]$.

\section{Interviews}

To gain deeper insight into students' thinking beyond what the written assessments revealed, we conducted student interviews across the transfer unit.

A subsample of $N=30$ students were asked by the teachers to participate in an interview study stretching four interview timepoints across the systems-transfer unit (in the following: T1-T4): just before the unit (T1), after learning set 2 (T2), learning set 3 (T3), as well as shortly after the end of the unit (T4). Based on a request from the researchers to identify a sample of students who they felt would be comfortable being interviewed and who represented a range of student abilities in their classes, the participating teachers selected two to three interviewees from each of their classes. All interviews were conducted by authors of this article. Based on their total score on curriculum-based tasks, the interview sample is representative for the sample as a whole $(t(230)=0.94, p=.35, d=0.2)$.

At each of T1-T4, students were interviewed according to a structured interview protocol (Online Supplement S2), following an adapted version of the interviewsabout-instances method (Osborne \& Gilbert, 1980). In this protocol, students were shown short videos (ca. 10s) of a series of phenomena and asked "How would you explain this phenomenon?". Students were not specifically asked to use energy ideas or other concepts from the unit to make sense of the phenomenon. After students' initial response, non-instructional follow-up questions using the language of the students were used to clarify ambiguous or unclear student statements. The interviewers were instructed not to use directional prompts, directional feedback, or conceptual clarification questions. If interviewers accidently used any of these, the respective sections of the interviews were not considered for analysis.

Table 1 gives an overview of the phenomena used in the interviews - falling ball/bouncing ball, melting ice, golf ball, and spinning cup. The phenomena were generally familiar to the students as similar ones were addressed in the unit at some point. 
Table 1 Overview of phenomena in the interviews-about-instances at the different measurement time points (T1-T4)

\begin{tabular}{ll}
\hline $\begin{array}{l}\text { Measurement } \\
\text { point }\end{array}$ & $\begin{array}{l}\text { Phenomenon and explanation } \\
\text { T1, T4 }\end{array}$ \\
& $\begin{array}{l}\text { Bouncing ball. A basketball is being let go by } \\
\text { a person, drops to the ground and then re- } \\
\text { bounds until it stops. } \\
\text { Phenomenon addressed in the curriculum be- } \\
\text { fore T4. }\end{array}$ \\
T2, T3 & $\begin{array}{l}\text { Falling ball. A ball is being let go and falls out } \\
\text { of the frame. }\end{array}$ \\
& $\begin{array}{l}\text { Phenomenon addressed in the curriculum be- } \\
\text { fore T3. }\end{array}$
\end{tabular}
fore T3.

Sample picture

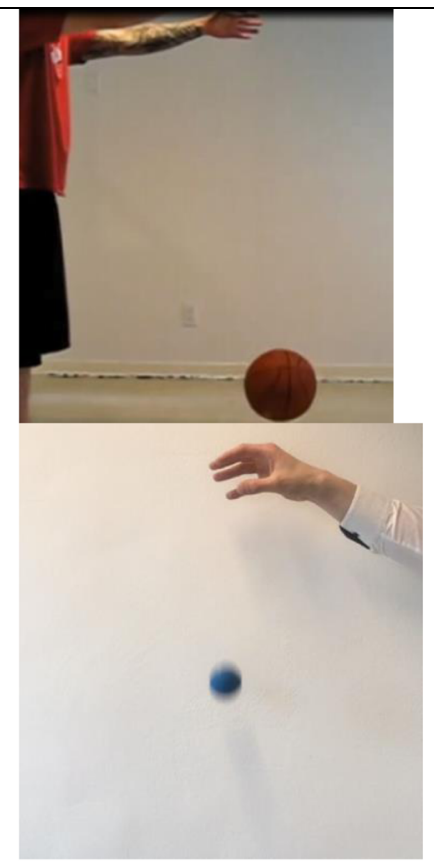

$\mathrm{T} 2$

Golf ball. A golf ball rolls into the frame and stops on a pile of gravel.

Similar phenomenon addressed in the curriculum before T4.

T1, T4 Spinning cup. A paper cup with tilted ventilation slits is suspended upside-down over a small sterno candle. As the warm air over the candle rises, the cup starts spinning.

Phenomenon addressed in the curriculum before T3.

T1, T4

Melting ice cubes. Two similar ice cubes are each placed on a plate, the latter of which being identical in temperature, size, and color. Unbeknownst to the interviewee (at T1), one is made of high-density foam the other of aluminum.
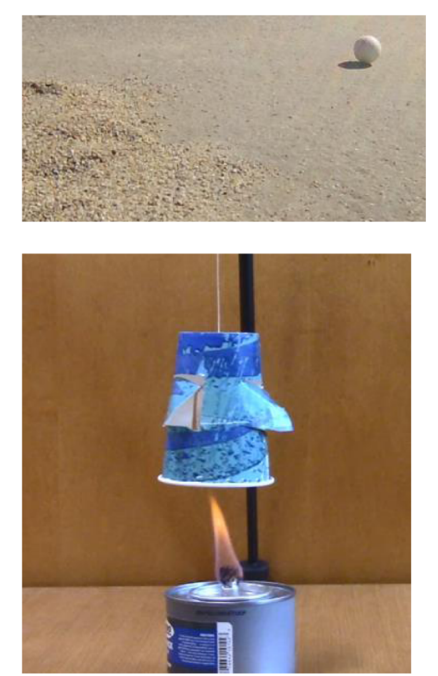

Phenomenon addressed in the curriculum be-

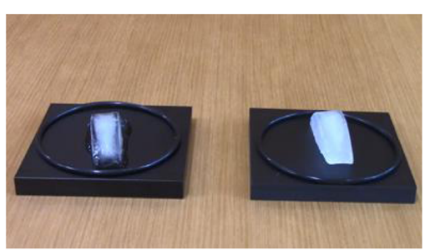
fore T4. 
The phenomena bouncing ball, melting ice, and spinning cup were used at $\mathrm{T} 1$ and $\mathrm{T} 4$ to investigate how students use ideas about fields when they explain phenomena that involve interaction-at-a distance between atomic scale and macroscopic objects. Further, the phenomena involve dissipation. Phenomena that involve dissipation are interesting because students are known to struggle with conservation in dissipative phenomena and the transfer-only perspective may support students in developing conservation ideas.

For T2 and T3, we employed fewer and simpler phenomena (falling ball, golf ball) in order to account for time limitations and in order to use phenomena that focused more closely on the ideas students had learned about at the respective points in the unit (see design proposal for interviews-about-instances, (Osborne \& Gilbert, 1980)).

\section{Analyses}

Due to the qualitative nature of our research questions, we mostly drew on the interview data in order to answer them. All qualitative analysis followed the framework for qualitative content analysis by Mayring (2014). In the following two sections, we describe how we developed the coding frameworks for each research question based on the relevant literature.

\section{Research question 1}

In order to investigate to what extent students progressed towards an understanding of conservation and how they apply it, we drew on the interviews because the follow-up prompts allowed to clarify the often ambiguous language use of students (Lemke, 1993). For example, when a student writes "energy is lost" it is often not possible to determine whether the student thinks that energy is being used up, contradicting the idea of energy conservation, or thinks that energy is dissipated but uses language more rooted in everyday language.

A qualitative understanding of conservation can be characterized by acknowledging that energy has to be somewhere at all times, i.e., when the energy in a system changes, there needs to be a transfer to or from some other system. This aligns with how energy conservation is characterized at the middle school level in the NGSS energy framework (Gray et al., 2019) and how, e.g., Herrmann-Abell and DeBoer (2017) align the intermediate level of conservation in their energy learning progression. Thus, students that have developed a qualitative understanding of conservation should a) track energy successfully, i.e., explain changes in the energy of one system by transfers to or from other systems, and b) not violate the principle of energy conservation. Further, we argue that applying a qualitative understanding of conservation allows reasoning productively about phenomena, e.g., when a student tries to track the energy of a ball that hit the ground, that may initiate multiple scientific practices such as asking questions, thinking about possible investigations, or model based reasoning (Tobin et al., 2018, 2019).

In order to investigate to what extent students' usage of energy ideas in the interviews was in line with a qualitative understanding of conservation and showed evidence of applying that understanding productively, we conducted a deductive qualitative content analysis based on Mayring (2014). We focused our analysis regarding students' development of a qualitative understanding of conservation on the three phenomena that were part of the $\mathrm{T} 1$ and $\mathrm{T} 4$ interviews (bouncing ball, spinning cup, melting ice) in order to allow for a meaningful comparison, as we could expect explanations related to conservation ideas from them. With respect to the analysis of productive reasoning, we also drew on the phenomena that were administered only once. In addition, we also coded to what extent student answers aligned with a forms-based or transfer-only perspective across all interview timepoints.

In our analysis, phrases served as a coding unit and the complete explanatory account of one phenomenon as an evaluation unit. All categories were revised multiple times and formulated using positive and negative coding instructions, as well as anchoring examples. Following recommendations by Mayring (2014), an analysis of inter-rater reliability was conducted with roughly $18 \%$ of the units of analysis and two raters. We found good agreement $K=0.88 \pm 0.03 \mathrm{SE}$ (Landis \& Koch, 1977) between the raters. Online Supplement S3 shows the category system.

\section{Research question 2}

In order to investigate how students used fields ideas in conjunction with energy ideas, we proceeded analogously to research question 1 but used a mixed approach of deductive and inductive elements: we used deductive categories to analyze to what extent students used fields ideas in normative ways. The deductive categories are based on the fields-related energy ideas in the transferonly unit and the Next Generation Science Standards (e.g., energy can be stored in and transferred to and from fields). We formulated inductive categories for non-normative usages as we went through the material. The categories for non-normative uses were revised in a second run through the material. Online Supplement S3 shows the final category system.

In order to compliment the qualitative picture from the interviews, we drew on quantitative data from the standard-based assessments students took as part of the post-test. This test included one task that required fields ideas and five tasks that did not. I order to investigate to what extent fields introduce additional difficulty that 
may limit the accessibility of the transfer-only approach, we compared how differently-achieving students scored on the task that requires fields ideas and those tasks that do not require fields. We split the sample based on students' average grade across mathematics, science, and English as a proximal measure for general achievement: low-achieving students with a grade average below the 25th percentile, high-achieving students with an average grade above the 75 th percentile, and medium-achieving students whose grade was between the 25th and 75th percentile.

\section{Results}

\section{Research question 1}

\section{Students' progress towards conservation}

We first provide a broad picture of how students' usage of energy ideas when explaining phenomena changed over the course of the unit.

Figure 5 shows that at the beginning of the unit, students rarely used energy ideas in order to explain the bouncing ball, the spinning cup, and the melting ice phenomenon, all of which involve dissipation. About half of the energy-based explanations aligned with ideas about energy forms. In most of the energy-based explanations, students violated energy conservation. At T2 and T3, students' usage of energy ideas had increased. By T3, most explanations aligned with a transfer-only perspective, i.e., in their explanations, students identified energy transfers between systems and processes that those systems undergo. At the end of the unit, only a small number of the energy-based explanations relied on forms of energy. In addition, the vast majority of energybased explanations showed correct tracking, i.e., at the end of the unit most explanations that used energy ideas tracked energy successfully in dissipative phenomena as it transfers across systems. In some cases, the interviews did not allow us to decide whether students tracked energy successfully or violated conservation.

I order to illustrate how these changes are manifested in students' explanations, we focus on the example of the bouncing ball phenomenon (observed patterns are generally similar across phenomena). At T1, only few explanations used energy ideas and most explanations, like the following, drew on force related ideas:

Example 1: Student A, T1, bouncing ball phenomenon - Force-related ideas;

Student: So, it keeps on bouncing up and down because gravity pulls it down and the ball has air in it, so it goes back up. And it continues to do so until it doesn't have enough pull, I guess.

While ideas about forces and gravity can be used to explain the bouncing of the ball, the quote shows the student's struggle in using these ideas in a normatively correct way. Similarly, students that use energy ideas struggle to explain the phenomenon. Energy ideas are used descriptively, not going beyond labeling, or energy is used in non-normative ways, violating conservation:

Example 2: Student B, T1, bouncing ball phenomenon - Labeling;

Interviewer: Can you describe what's happening to the ball?

Student: Um, as it goes down it has um, kinetic, if I'm correct, 'cause it's moving.

Interviewer: Ok.

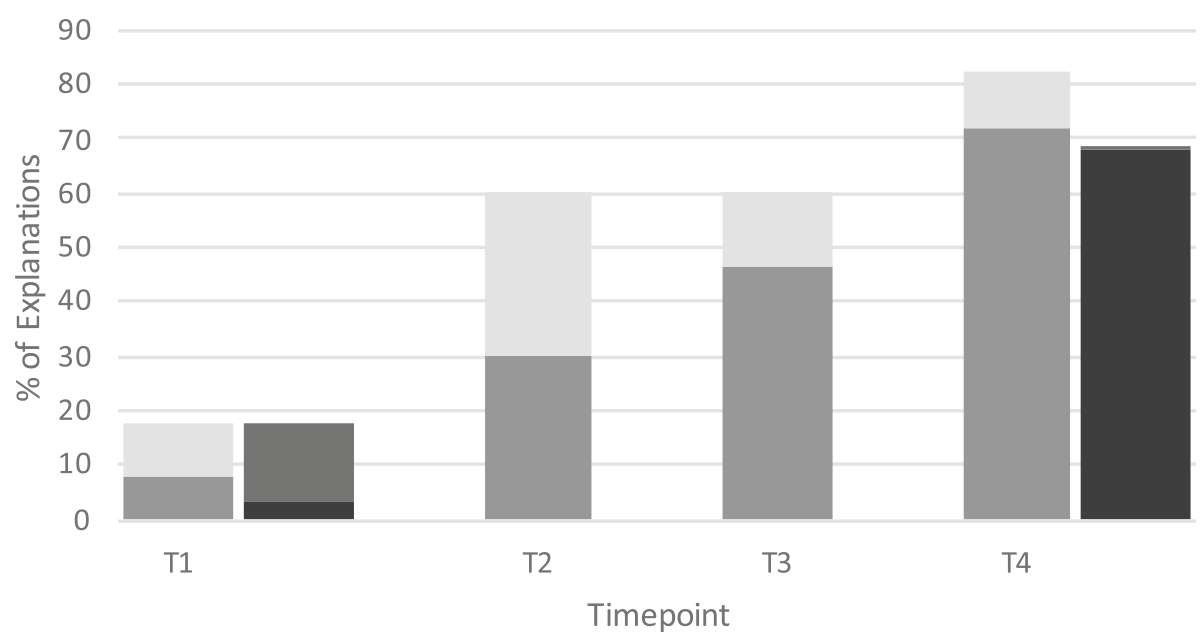

- Transfer-only Forms-based Correct tracking Conservation violated

Fig. 5 Distribution of codes for students' usage of energy ideas across the unit and all phenomena 
Student: Then when it's going up, I forgot what the other one was called. But it turns into another one.

Example 3: Student C, T1, bouncing ball phenomenon - Violating conservation

The ball, like, it's filled with air, and then when it hits the ground, we can't see it because it happens too quick but it pushes down and then falls down. And then, the kinetic energy pushes it back up. And then, it does that until it runs out of kinetic energy - because it can't, like, mix potential and kinetic energy. So, it doesn't have all of its' energy. And, eventually, it just runs out of energy and stops.

At the end of the unit, most students drew on a transfer-only perspective to explain the bouncing ball. While not all explanations are normatively correct, e.g., students get the direction of energy transfers wrong, almost all students track energy successfully, that is, do not violate conservation. I order to illustrate this, we present the corresponding T4 answers for the student that initially drew on force ideas:

\section{Example 4: Student A, T4, bouncing ball} phenomenon

Student: When the ball drops, it obviously releases energy to the air and to the ground so, therefore, when it's going back up, it's not going to have enough energy to go all the way up.

Interviewer: Ok, how would you be able to prove that, somehow, that energy is transferred to the ground and to the air?

Student: At the very top, it has no energy but as it falls; the energy from the gravitational field basically transfers energy to the ball which speeds it up and when it hits the ground it loses some of that energy which transfers back to the gravitational field when it goes back up. That has energy and then when it goes back, it continues to keep on doing that and then, yeah, it eventually stops, because it has no more energy to transfer back.

The student explains the decreasing height of the ball with an energy transfer from the ball to the air and the ground which over time leads to a decrease of energy in the ball system. While the student says that the ball loses energy after the question by the interviewer, the initial statement makes it clear that "lose" referred to a transfer to the air and ground. In sum, the student has progressed towards a correct, transfer-only based explanation of a dissipative phenomenon.
The student that initially used energy mostly by labeling energy forms (Example 2), provided this explanation at T4:

Example 5: Student B, T4, bouncing ball phenomenon

Student: When he drops the ball and it hits the ground, it transfers energy to the gravity field, then it transfers energy to the ball which it makes it go up. Like it wouldn't have as much energy in step four, that's why it isn't about as high as he dropped and it keeps repeating that until there is no energy left.

Interviewer: Why is it not going so high on the second bounce and the third bounce?

Student: It is because it has less energy than before it was dropped because it keeps transferring energy to the gravitational field every time it hits the ground.

Here, the student confuses the system to which energy is transferred when the ball hits the ground. Thus, this answer cannot be considered normatively correct but still presents an instance of tracking energy successfully.

Lastly, the student that initially violated conservation (Example 3) explained the bouncing ball like this at the end of the unit:

Example 6: Student C, T4, bouncing ball phenomenon

Every time the ball drops, energy is transferred a little bit into the floor and the surroundings each time until eventually it runs out of energy and can't bounce any higher.

While this student's explanation does not elaborate on the role of the gravitational field, it explains the decreasing height of the bouncing ball from a transfer-only perspective and in contrast to the earlier explanation at T1 without violating conservation.

In sum, students' explanations of the bouncing ball at the end of the unit were not all normatively correct (only 19 out of 30), but perhaps more importantly, we only found one case where a student did not track energy successfully in this dissipative phenomenon as compared to eight cases prior to the unit. This change becomes more significant when one considers that prior to the unit, only 10 students used energy ideas at all whereas 29 students used energy ideas at the end of the unit. In other words, prior to the unit, 4 out of 5 students who used energy ideas violated energy conservation, while after the unit, this was practically absent. 


\section{How students apply conservation ideas}

We found evidence of students using energy productively in the falling ball and golf ball phenomenon at T2. When students tried to explain the falling ball at T2, they had not been introduced to the concept of fields yet. Thus, it remained unclear for students where the energy in the falling ball phenomenon that was evidently transferred to the falling ball was coming from:

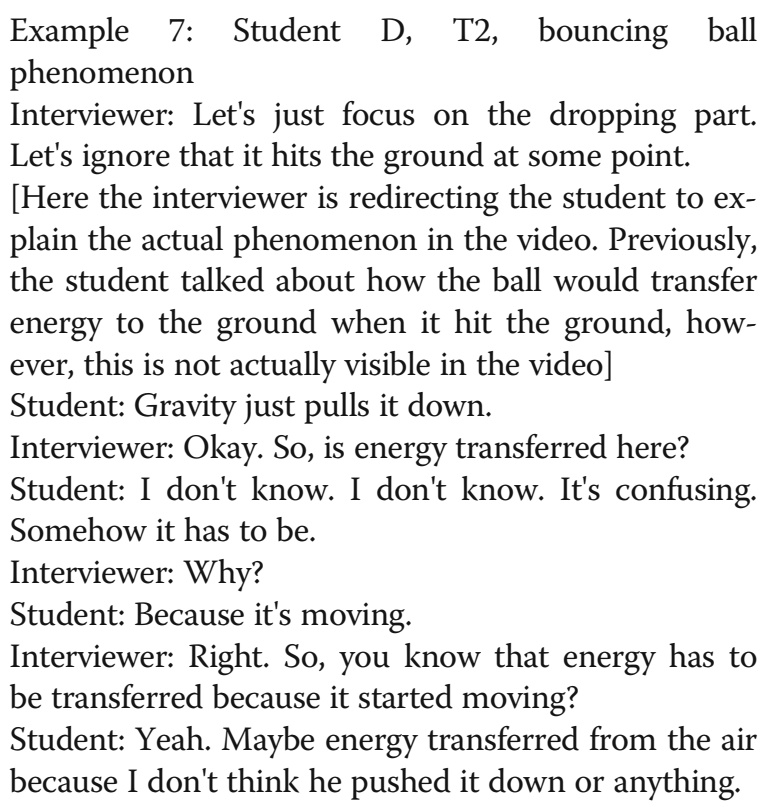

In example 7, the interviewer first refocuses the student on the actual phenomenon. Then, the student voices their confusion. The ball is starting to move, thus there has to be an energy transfer to it. However, there is no obvious other system that the energy is being transferred to. Thus, the student speculates that energy might have been transferred to the air. The excerpt shows how the implicit notion of energy conservation in the transfer-only approach, i.e., that energy has to be somewhere at all times, leads to productive reasoning about a system where the energy that is transferred to the ball might have come from.

In the golf ball phenomenon, students saw a golf ball rolling into the frame and stopping on sand. However, there was no visible evidence of the gravel undergoing some change, leading to students hypothesizing about what change the sand might undergo in consequence of energy being transferred from the golf ball to the sand:

Example 8: Student E, T2, golf ball phenomenon Student: The golf ball is rolling and then the sand, and it hits a patch of sand and it stops.

Interviewer: Right, okay, can you explain that to me? Student: The golf ball is losing energy, so it would stop.
Interviewer: Okay, now wait. You said a few things and I want to follow up on. So, you said the golf ball is losing energy.

Student: Yeah, because it stopped.

Interviewer: Okay, so your indication of losing energy is what?

Student: Stopping. And the sand if it gains energy, I don't know because of whether the sand doesn't move.

Interviewer: Okay, so that's actually interesting. Why are you assuming that the sand gained energy?

Student: Because that has to, the energy has to go somewhere.

Interviewer: Ok, so you said, "Sand," but then you said it couldn't be the sand.

Student: No.

Interviewer: Why can't it be the sand?

Student: Because it's not moving anywhere. It's not doing really anything.

Interviewer: Right because if the golf ball was actually transferring energy to the sand, the sand ...

Student: Would move.

Interviewer: Is that its only option?

Student: Temperature?

Based on the premise that energy has to "go somewhere", the student questions their first choice, the sand, because they could not observe any change occurring in the sand system. This then leads to a dialog of productive reasoning about other possible changes that the sand might have undergone when energy from the ball was transferred to it.

The instances of productive reasoning guided by the notion that energy always has to be somewhere, i.e., qualitative conservation, presented here have not lead to normatively correct answers (the energy transferred to the falling ball does not come from the air). However, it is easy to see how the related questions reflect first steps in scientific practices like asking questions that could easily be built upon in a classroom setting and generate new insight into phenomena for students.

\section{Research question 2}

In the interviews at $\mathrm{T} 3$ and $\mathrm{T} 4$, roughly two thirds of the students used fields ideas in the phenomena that involved macroscopic interactions-at-a-distance. Those usages were distributed across the different ways in which students used fields in the following way: $11 \%$ only mentioned fields but did not relate them to energy or interactions-at-a-distance, $26 \%$ used fields in order to account for interactions-at-a-distance, 39\% used fields in the sense that energy can be transferred to or from them, and about $24 \%$ used fields in the latter two ways. 
Example 9 from the falling ball phenomenon illustrates the usage of fields to account for interactions-at-adistance:

Example 9: Student G, T2, falling ball phenomenon Interviewer: What happened in the video?

Student: A girl dropped a basketball from a significant height and Earth's gravitational field pulled it down.

For these students, fields appear to primarily mediate interactions-at-a-distance and they use this idea normatively correct in the interviews.

Example 10 reflects a normatively correct usage of fields in the sense of systems that energy can be transferred to or from:

Example 10: Student J, T3 falling ball phenomenon The ball gets energy from the gravitational field as it gets closer to the ground. Then energy goes to the ground and the it goes back up. And the rest keeps going through the ball and the gravitational field. And the ball stops because eventually all energy goes in the ground.

Further, 25\% used both aspects of the fields idea together, i.e., fields as mediating interaction-at-a-distance and fields as systems that energy can be transferred to or from. In all of these instances, students talk about fields similarly to the way they talk about any other system such as the falling or bouncing ball, i.e., students treat fields like entities.

However, when students used fields ideas in the sense of systems that energy can be transferred to or from, we also observed non-normative uses in about a third of the instances where students used fields ideas. In these cases, such as in example 11, students confused the direction of the energy transfer, e.g., some students said that energy is transferred from the ball to the gravitational field:

Example 11: Student I, T3, falling ball phenomenon Interviewer: So what happens here?

Student: A guy drops a ball.

Interviewer: Right.

Student: And then when it's dropping, it gives energy to - well, yeah, it gives energy to the gravitational field.

These non-normative uses can be conceptualized in two ways: First, students appear to mix up fields and related systems within a chain of energy transfers. Second, when they use the term field, it appears to be a receptacle for energy that is currently not clearly observable, without need to focus more closely on how energy is stored in and given off of the field (e.g., by a stretch in the fields between atoms).

The aforementioned results focused on fields that mediate interactions-at-a-distance between macroscopic objects. We also introduced fields as interactions-at-adistance between atomic scale objects. However, only three students used the idea of fields on the atomic scale level, both in the bouncing ball phenomenon:

\section{Example 12: Student J, T4 bouncing ball phenomenon}

Student: Um, a guy is holding a ball up. It has stored uh, energy in the gravitational field by holding it there. Then he releases it. It hits the ground. When it hits the ground, it distributes a little bit of energy and it, like, puts energy into the particle field. But a little bit of it goes into the ground, which distributes. And then it un-smooshes and goes back up, but a little bit of the energy was lost to the ground so it doesn't go all the way back up.

In example 12, the student correctly asserts that when the ball compresses, some energy is transferred to the field between the atoms of the ball and some energy is transferred to the ground and then explains the decreasing height of the ball's bounces via the energy that is transferred to the ground. While this student used fields on the atomic scale level correctly, the low number of students using fields on the micro level suggests that fields on the micro level are more challenging or appear less useful/accessible than fields on the macro level, especially, since student overall did use ideas about particles and particle motion in their explanations.

With regards to research question 2 , we were also able to draw on the analysis of quantitative data from students' post-tests after the unit. The analysis of the quantitative data revealed no evidence that the fields concept poses an undue challenge to students at the macroscopic level: Fig. 6 shows the average scores for low, medium, and high-performing students for each task on the post test. MS.E_08 was the only task that required fields ideas. As the figure shows, low-achieving students' average score on this task is similar to low-achieving students' average score across tasks that did not require fields (horizontal line) and well within the respective 95\% confidence interval. This suggesting that lowperforming students were no more challenged by tasks that required them to use fields than tasks that did not.

\section{Discussion}

Conservation is at the heart of the energy concept as it provides a lens for investigating and analyzing a wide 


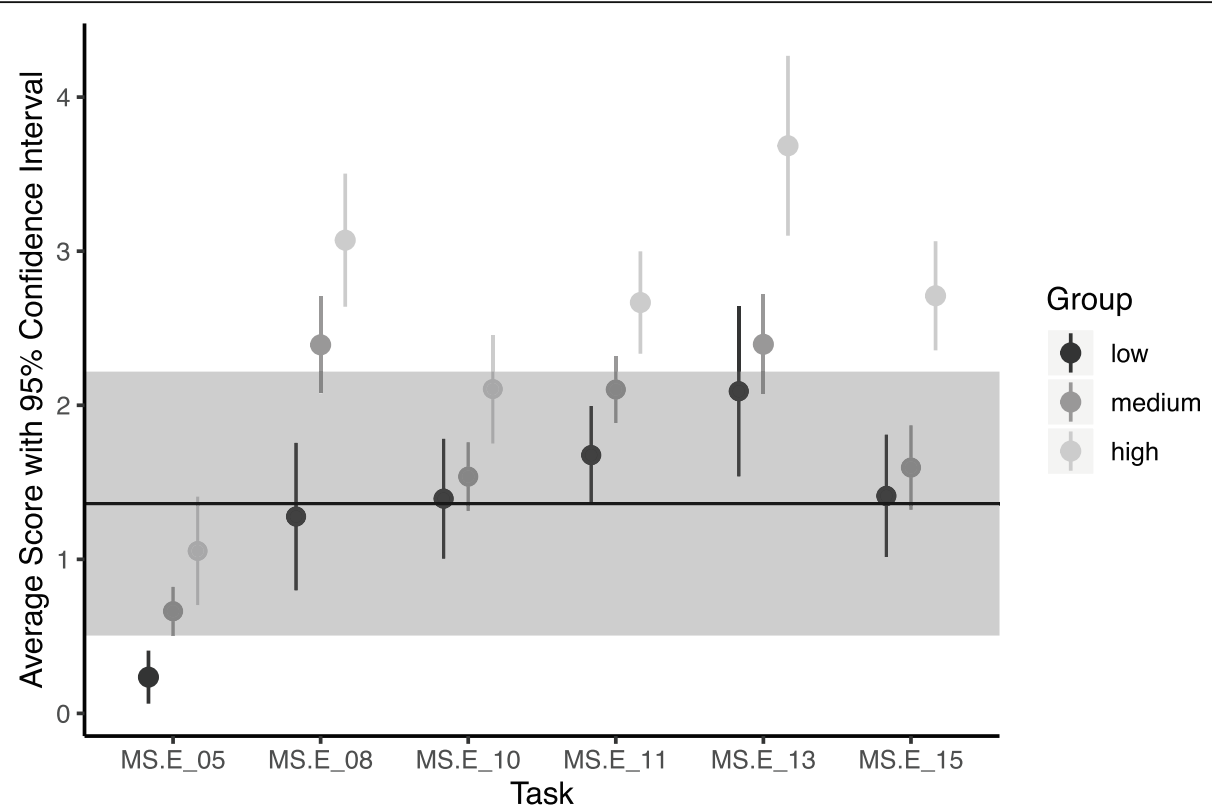

Fig. 6 Average score of low, medium, and high-achieving students on the post-test. Horizontal line and grey box represent average scores of low-achieving students in non-fields tasks and 95\% confidence interval. MS.E_08 is the only task that required fields ideas

range of phenomena. However, in the predominant approach of conceptualizing energy in terms of forms, only few students develop an understanding of conservation (e.g., Herrmann-Abell \& DeBoer, 2017). We studied to what extent students in a transfer-only approach that does not require forms progress towards an understanding of conservation.

A potential challenge associated with the transfer-only approach is that it requires introducing fields. Similar to energy, fields are a fundamental concept in physics which is challenging - even for students at the undergraduate level. However, students' difficulty in understanding may be related to how fields are usually introduced - as mathematical abstractions in the context of forces.

\section{Research question 1 - a different pathway towards conservation}

Our results indicate that students in the transfer-only unit progress towards a qualitative understanding of conservation without relying on forms ideas. Students appeared to be using energy in a productive way so that they might be pushed towards investigating the respective phenomenon more deeply.

Our finding that students' progress towards a qualitative understanding of energy conservation - as they successfully track energy across systems and do not violate conservation - adds a new perspective to the existing energy learning progressions literature (Herrmann-Abell \& DeBoer, 2017; Liu \& McKeough, 2005; Neumann et al., 2013) as it points towards a productive alternative pathway in order for students to develop a set of robust and useful ideas about conservation. This is substantially different from prior studies that investigated specific curricular approaches and found that only few students progressed towards conservation (Bächtold \& Munier, 2018; Nordine et al., 2011). The main difference between these studies and the study at hand is that all earlier approaches to energy teaching introduced energy forms at some point while the transfer-only approach does not. This suggests that energy learning progressions may not have to go through forms; a different pathway may in fact be more productive.

This different pathway may be more productive because the approach aligns with a substance metaphor for energy. Numerous authors have argued that using a substance metaphor with energy emphasizes that energy is conserved and may thus support students in progressing towards conservation (Amin, 2020; Brewe, 2011; Duit, 1987; Falk et al., 1983; Scherr, Close, McKagan, \& Vokos, 2012b; Swackhamer, 2005). These arguments have been supported by episodic evidence from several studies indicating that energy representations which align with a substance metaphor support students in tracking energy successfully and using energy ideas productively to reason about phenomena (Daane et al., 2015; Kubsch, Nordine, Fortus, Krajcik, \& Neumann, 2019; Lacy, Tobin, Wiser, \& Crissman, 2014; Scherr, Close, Close, \& Vokos, 2012a; Tobin et al., 2019). When students in the transfer-only unit locate energy in systems and talk about how it transfers between them, this aligns with a substance metaphor. Essentially, this allows 
students to use their long-learned knowledge that matter does not simply disappear or appear, i.e., that matter is conserved. In turn, productive question like "Where has the energy gone?" (Tobin et al., 2019) turn into a productive heuristic that allows students to apply conservation ideas when reasoning about phenomena. A potential problem of emphasizing the substance metaphor is that it may promote the conception that energy is a substance. However, this potential problem has not yet been supported by empirical evidence (Scherr, Close, McKagan, \& Vokos, 2012b) and neither has our study found such evidence. Further, Vosniadou \& Skopeliti (2019) found that drawing on existing reasoning patterns in learning about new complex ideas does not lead to an increase in students' misconceptions, thus suggesting that using a substance metaphor must not necessarily lead to more misconceptions about the nature of energy. Lastly, one may argue that relying on a substance metaphor in introductory energy instruction will lead to confusion later because at some point, one will have to discuss that energy is not a substance. However, emphasizing that the substance metaphor is a model of energy (Gray et al., 2019; Harrer, 2017; Scherr, Close, McKagan, \& Vokos, 2012b) provides valuable opportunities to integrate the scientific practice of modeling into the disciplinary core idea of energy to foster knowledge-in-use, e.g., by discussing the applicability, usefulness, and limits of the substance metaphor, all important aspects of the practice of scientific modeling (NGSS Lead States, 2013).

When emphasizing a substance metaphor in energy instruction supports progress towards conservation, this raises the questions about the need for energy forms on a purely qualitative level. While forms can align with a substance metaphor (Scherr, Close, McKagan, \& Vokos, 2012b), e.g., when kinetic energy is transferred in a collision between two balls, transformations of energy forms do not necessarily align with a substance metaphor (Reiner, Slotta, Chi, \& Resnick, 2000). However, without transformations of energy, an analysis of only energy forms adds little insight into phenomena (Kaper \& Goedhart, 2002a). This changes when energy instruction transitions towards a quantitative perspective. Now, the formulas associated with forms clearly become useful. In consequence, we suggest rethinking the energy learning progression and the need-to-know about forms: At least in introductory middle school instruction, forms may provide more insight when they are introduced in order to answer quantitative questions after students have developed a qualitative model of energy rooted in a substance metaphor.

\section{Research question 2: fields in the context of energy}

We found that, when treated as real entities and introduced in the context of energy, middle school students can develop a beginning understanding of fields between macroscopic objects as mediating interactions-at-a-distance and systems that energy can be transferred to or from. They seem to readily assign fields with an ontological status (at least in terms of energy transfer) that is similar to that of an object.

When middle school students account for interactions-at-a-distance by drawing on the idea of a field, e.g., an energy transfer from the gravitational field between the earth and a ball to a falling ball, they have made promising progress. First, students' language suggests that they consider fields as physical entities or systems. This is an important part of a Maxwellian conceptual profile of fields (Furio \& Guisasola, 1998) that is foundational to modern physics. Conceptualizing fields as physical systems may support long-term learning about electromagnetism (Herrmann, 1989). Second, when students locate the energy that is transferred to the falling ball in the gravitational field between the ball and the Earth, they assign what would be labelled 'potential energy' in a forms-based approach to the correct system. As results by Lindsey et al. (2012) show, this alone is already a substantial step. For example, in the case of the falling ball, students in a forms-based approach often assign potential energy to the ball alone or they do not identify potential energy at all (e.g., Forde, 2003). Further, it supports the argument put forward by Quinn (2014) that fields may help students correctly locate potential energy. Lastly, it demonstrates that emphasizing the close connections between fields and energy stressed in the Framework for K-12 Science Education and the US Next Generation Science Standards is feasible in middle school. While generally positive, our results also suggested that some students seemed to use fields as a catch-all phrase when there was no obvious system that energy could be transferred to. This is similar to forms-based approaches where non-normative usages of heat, thermal energy, and potential energy have been recorded (Kaper \& Goedhart, 2002a, 2002b).

\section{Limitations}

Our results from the interviews are limited in generalizability by the relatively small number of different phenomena and their focus on mechanics. In future studies, it would be interesting to explore how students in a transfer-only approach use fields, energy, and systems ideas to make sense of biological and more pronounced chemical phenomena.

Another limit to generalizability comes from the relatively small sample. Thus, our results do not reflect the whole bandwidth of progress towards conservation or usages of fields and energy ideas in explanations. Further qualifying these results remains for future work while the present study rather provides proof of existence. 
While we found no evidence that fields put lowerachieving students at a disadvantage based on students' performance on the post-test, the robustness of this finding is limited as the number of tasks is limited. Future research would benefit from developing a larger inventory of tasks to compare the difficulty of tasks that require fields and tasks that do not.

Lastly, fields between atomic-scale objects appear to be a limit in 7th grade. To what extent these two challenges in introducing fields in the context of energy are generalizable or rather rooted in the specifics of our sample or instructional unit remains an issue for future research.

\section{Conclusion and future directions}

Taken together, our findings add to the literature by demonstrating that an alternative, potentially productive pathway towards conservation exists and providing first insights into the promises and challenges of introducing fields as real entities in the context of energy rather than mathematical abstraction in the context of forces. To what extent long term progress towards quantitative conservation is possible in a transfer-only approach will need to be explored in future research.

While the research into energy learning progressions has repeatedly demonstrated that students rarely progress towards conservation, research into alternative progressions has been rare. Instead, research has focused on different pedagogical approaches (e.g.Bächtold \& Munier, 2018; Papadouris \& Constantinou, 2011). The open exploration of alternative pathways may have been halted by what Kapur (2016) calls unproductive success, i.e., initial promising progress that does not translate into long-term competence. After all, learning progressions research showed that students readily progress from forms to transformation. We wonder to what extent learning progressions in other challenging domains such as evolution may also be stuck in unproductive success and hope that an open exploration of possible alternative pathways will be considered.

\section{Supplementary Information}

The online version contains supplementary material available at https://doi. org/10.1186/s43031-020-00030-7

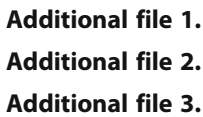

\section{Acknowledgements}

We thank all teachers who helped with the development of the Transferonly energy unit and we are grateful to the students who spent their recess in our cold interview room. We also thank the anonymous reviewers for providing us with valuable feedback and the NSF for funding our work. We thank Elisabeth von Breslau for language editing.

\section{Authors' contributions}

MK analyzed and interpreted the data and wrote the manuscript. SO contributed to data analysis and interpretation and writing the manuscript. JN contributed to the design, data interpretation and revising the manuscript. KN contributed to the design and data acquisition. DF contributed to the design and data acquisition. JK contributed to the design and data acquisition. The author(s) read and approved the final manuscript.

\section{Funding}

This research was funded by the National Science Foundation under grant DUE-1431725. The opinions expressed herein are those of the authors and not necessarily those of the NSF.

\section{Availability of data and materials}

The datasets used and analyzed during the current study are available from the corresponding author on reasonable request.

Ethics approval and consent to participate

The institutional review board at Michigan State University (MI, USA) approved of the study.

All participants expressed consent to participate.

\section{Consent for publication}

Not applicable.

\section{Competing interests}

The authors declare that they have no competing interest.

\section{Author details}

${ }^{1}$ Department of Physics Education, Leibniz-Institute for Science and Mathematics Education (IPN), Kiel, Germany. ${ }^{2}$ Department of Biology Education, Leibniz-Institute for Science and Mathematics Education (IPN), Kiel, Germany. ${ }^{3}$ Department of Science Teaching, Weizmann Institute of Science, Rehovot, Israel. ${ }^{4}$ CREATE for STEM Institute, Michigan State University, East Lansing, MI, USA.

Received: 18 September 2020 Accepted: 20 December 2020 Published online: 26 January 2021

\section{References}

Amin, T. (2020). Coordinating metaphors in science, learning and instruction: The case of Energy1.

Bächtold, M., \& Munier, V. (2018). Teaching energy in high school by making use of history and philosophy of science. Journal of Research in Science Teaching. https://doi.org/10.1002/tea.21522.

Bradamante, F., \& Viennot, L. (2007). Mapping gravitational and magnetic fields with children 9-11: Relevance, difficulties and prospects. International Journal of Science Education, 29(3), 349-372 https://doi.org/10.1080/ 09500690600718245.

Bransford, J. (2000). How people learn: Brain, mind, experience, and school (National Research Council (U.S.), Ed.; Expanded ed). National Academy Press.

Brewe, E. (2011). Energy as a substancelike quantity that flows: Theoretical considerations and pedagogical consequences. Physical Review Special Topics - Physics Education Research, 7(2), 020106 https://doi.org/10.1103/ PhysRevSTPER.7.020106.

Chabalengula, V. M., Sanders, M., \& Mumba, F. (2012). Diagnosing students' understanding of energy and its related concpets in biological contexts. International Journal of Science and Mathematics Education, 10(2), 241-266 https://doi.org/10.1007/s10763-011-9291-2.

Clark, D. B., \& Linn, M. C. (2013). The knowledge integration perspective: Connections across research and education. International Handbook of Research on Conceptual Change, 520-538.

Coopersmith, J. (2015). Energy, the subtle concept: The discovery of Feynman's blocks from Leibniz to Einstein (revised edition). Oxford: Oxford University Press.

Daane, A. R., Haglund, J., Robertson, A. D., Close, H. G., \& Scherr, R. E. (2018). The pedagogical value of conceptual metaphor for secondary science teachers. Science Education, 102(5), 1051-1076 https://doi.org/10.1002/sce.21451.

Daane, A. R., McKagan, S. B., Vokos, S., \& Scherr, R. E. (2015). Energy conservation in dissipative processes: Teacher expectations and strategies associated with imperceptible thermal energy. Physical Review Special Topics - Physics 
Education Research, 11(1), 010109 https://doi.org/10.1103/PhysRevSTPER.11. 010109.

Doménech, J. L., Gil-Pérez, D., Gras-Martí, A., Guisasola, J., Martínez-Torregrosa, J., Salinas, J., ... Vilches, A. (2007). Teaching of energy issues: A debate proposal for a global reorientation. Science \& Education, 16(1), 43-64 https://doi.org/10. 1007/s11191-005-5036-3.

Duit, R. (1987). Should energy be illustrated as something quasi-material? International Journal of Science Education, 9(2), 139-145 https://doi.org/10. 1080/0950069870090202.

Ellse, M. (1988). Transferring not transforming energy. School Science Review, 69(248), 427-437.

Falk, G., Herrmann, F., \& Schmid, G. B. (1983). Energy forms or energy carriers? American Journal of Physics, 51(12), 1074-1077.

Feynman, R. P. (1965). The Feynman lectures on physics; Vol. I. American Journal of Physics, 33(9), 750 https://doi.org/10.1119/1.1972241.

Forde, T. (2003). "When I am watching television I am not using any energy"- an empirical study of junior science students' intuitive concepts of energy. Irish Educational Studies, 22(3), 71-89 https://doi.org/10.1080/0332331030220309.

Fortus, D., Abdel-Kareem, H., Chen, J., Forsyth, B., Grueber, D., Nordine, J., \& Weizman, A. (2012). Why do some things stop while others keep going. Investigating and Questioning Our World through Science and Technology (IQWST). New York: Sangari Science.

Fortus, D., Kubsch, M., Bielik, T., Krajcik, J., Lehavi, Y., Neumann, K., ... Touitou, I. (2019). Systems, transfer, and fields: Evaluating a new approach to energy instruction. Journal of Research in Science Teaching, tea.21556 https://doi.org/ 10.1002/tea.21556.

Furio, C., \& Guisasola, J. (1998). Difficulties in learning the concept of electric field. Science Education, 82(4), 511-526.

Gray, K. E., Wittmann, M. C., Vokos, S., \& Scherr, R. E. (2019). Drawings of energy: Evidence of the next generation science standards model of energy in diagrams. Physical Review Physics Education Research, 15(1), 010129 https:// doi.org/10.1103/PhysRevPhysEducRes.15.010129.

Guerra, F., Leone, M., \& Robotti, N. (2014). When energy conservation seems to fail. Science \& Education, 23(6), 1339-1359 https://doi.org/10.1007/s11191-0129567-0.

Halliday, D., Resnick, R., \& Walker, J. (2005). Fundamentals of physics (7th ed., extended ed). Hoboken: Wiley.

Harrer, B. W. (2017). On the origin of energy: Metaphors and manifestations as resources for conceptualizing and measuring the invisible, imponderable. American Journal of Physics, 85(6), 454-460 https://doi.org/10.1119/1.4979538.

Harris, C. J., Krajcik, J. S., Pellegrino, J. W., \& McElhaney, K. W. (2016). Constructing assessment tasks that blend disciplinary core ideas, crosscutting concepts, and science practices for classroom formative applications.

Hecht, E. (2003). An historico-critical account of potential energy: Is PE really real? The Physics Teacher, 41(8), 486-493 https://doi.org/10.1119/1.1625210.

Herrmann, F. (1989). Energy density and stress: A new approach to teaching electromagnetism. American Journal of Physics, 57(8), 707-714 https://doi.org/ 10.1119/1.15925.

Herrmann-Abell, C. F., \& DeBoer, G. E. (2017). Investigating a learning progression for energy ideas from upper elementary through high school. Journal of Research in Science Teaching. https://doi.org/10.1002/tea.21411.

Hobson, A. (2013). There are no particles, there are only fields. American Journal of Physics, 81(3), 211 https://doi.org/10.1119/1.4789885.

Kaper, W. H., \& Goedhart, M. J. (2002a). "Forms of energy", an intermediary language on the road to thermodynamics? Part I. International Journal of Science Education, 24(1), 81-95 https://doi.org/10.1080/09500690110049114.

Kaper, W. H., \& Goedhart, M. J. (2002b). "Forms of energy", an intermediary language on the road to thermodynamics? Part II. International Journal of Science Education, 24(2), 119-137 https://doi.org/10.1080/ 09500690110049123.

Kapur, M. (2016). Examining productive failure, productive success, unproductive failure, and unproductive success in learning. Educational Psychologist, 51(2), 289-299 https://doi.org/10.1080/00461520.2016.1155457.

Krajick, J., Reiser, B., Sutherland, L., \& Fortus, D. (2012). IOWST: Investigating and questioning our world through science and technology. Greenwich, CT: Active Science.

Krajcik, J. S., \& Shin, N. (2014). Project-Based Learning. In R. K. Sawyer (Ed.), The Cambridge handbook of the learning sciences (2nd, pp. 275-297). Cambridge University Press. https://doi.org/10.1017/CBO9781139519526.018

Kubsch, M., Nordine, J., Fortus, D., Krajcik, J., \& Neumann, K. (2019). Supporting students in using energy ideas to interpret phenomena: The role of an energy representation. International Journal of Science and Mathematics Education. https://doi.org/10.1007/s10763-019-10035-y.

Lacy, S., Tobin, R., Wiser, M., \& Crissman, S. (2014). Looking through the energy lens: A proposed learning progression for energy in grades 3-5. In Teaching and learning of energy in K-12 education, (pp. 241-265). Springer.

Landis, J. R., \& Koch, G. G. (1977). The Measurement of Observer Agreement for Categorical Data. Biometrics, 33(1), 159 https://doi.org/10.2307/2529310.

Lehavi, Y., Eylon, B., Hazan, A., Bamberger, Y., \& Weizman, A. (2012). Focusing on changes in teaching about energy. In Proceedings of the world conference on physics education, (pp. 485-492).

Lemke, J. L. (1993). Talking science (2. pr). Ablex Publ http://gso.gbv.de/DB=2.1/ PPNSET?PPN=043257003.

Lindsey, B. A., Heron, P. R. L., \& Shaffer, P. S. (2012). Student understanding of energy. American Journal of Physics, 80(2), 154 https://doi.org/10.1119/1. 3660661.

Linn, M. C. (2006). The Knowledge Integration Perspective on Learning and Instruction. In The Cambridge handbook of: The learning sciences. Cambridge University Press.

Liu, X., \& McKeough, A. (2005). Developmental growth in students' concept of energy. Journal of Research in Science Teaching, 42(5), 493-517 https://doi. org/10.1002/tea.20060.

Mayring, P. (2014). Qualitative content analysis. Beltz.

Mislevy, R. J., \& Haertel, G. D. (2007). Implications of evidence-centered design for educational testing. Educational Measurement: Issues and Practice, 25(4), 6-20 https://doi.org/10.1111/j.1745-3992.2006.00075.x.

National Research Council (2012). A framework for K-12 science education. The National Academies Press http://www.worldcat.org/oclc/794415367.

Neumann, K., Viering, T., Boone, W. J., \& Fischer, H. E. (2013). Towards a learning progression of energy. Journal of Research in Science Teaching, 50(2), 162-188 https://doi.org/10.1002/tea.21061.

Neumann, K., \& Nagy, G. (2013). Students' progression in understandining energy. Puerto Rico: NARST Annual International Conference.

NGSS Lead States (2013). Next generation science standards. Washington: National Acad. Press.

Nordine, J., Fortus, D., Lehavi, Y., Neumann, K., \& Krajcik, J. (2018). Modelling energy transfers between systems to support energy knowledge in use. Studies in Science Education, 54(2), 177-206 https://doi.org/10.1080/03057267. 2018.1598048

Nordine, J., Krajcik, J., \& Fortus, D. (2011). Transforming energy instruction in middle school to support integrated understanding and future learning. Science Education, 95(4), 670-699 https://doi.org/10.1002/sce.20423.

Osborne, R. J., \& Gilbert, J. K. (1980). A technique for exploring students' views of the world. Physics Education, 15(6), 376.

Papadouris, N., \& Constantinou, C. P. (2011). A philosophically informed teaching proposal on the topic of energy for students aged 11-14. Science \& Education, 20(10), 961-979 https://doi.org/10.1007/s11191-010-9305-4.

Park, M., \& Liu, X. (2016). Assessing understanding of the energy concept in different science disciplines. Science Education. https://doi.org/10.1002/sce. 21211.

Quinn, H. R. (2014). A physicist's musings on teaching about energy, (p. 15) https:// doi.org/10.1007/978-3-319-05017-1_2.

Reiner, M., Slotta, J. D., Chi, M. T. H., \& Resnick, L. B. (2000). Naive physics reasoning: A commitment to substance-based conceptions. Cognition and Instruction, 18(1), 1-34 https://doi.org/10.1207/S1532690XCl1801_01.

Scherr, R. E., Close, H. G., Close, E. W., \& Vokos, S. (2012a). Representing energy. II. Energy tracking representations. Physical Review Special Topics - Physics Education Research, 8(2) https://doi.org/10.1103/PhysRevSTPER.8.020115.

Scherr, R. E., Close, H. G., McKagan, S. B., \& Vokos, S. (2012b). Representing energy. I. Representing a substance ontology for energy. Physical Review Special Topics - Physics Education Research, 8(2) https://doi.org/10.1103/ PhysRevSTPER.8.020114.

Solomon, J. (1985). Teaching the conservation of energy. Physics Education, 20(4), 165-170 https://doi.org/10.1088/0031-9120/20/4/307.

Swackhamer, G. (2005). Cognitive resources for understanding energy.

Tobin, R. G., Crissman, S., Doubler, S., Gallagher, H., Goldstein, G., Lacy, S., ... Wagoner, P. (2012). Teaching teachers about energy: Lessons from an inquiry-based workshop for K-8 teachers. Journal of Science Education and Technology, 21(5), 631-639 https://doi.org/10.1007/s10956-011-9352-x.

Tobin, R. G., Lacy, S. J., Crissman, S., \& Haddad, N. (2018). Model-based reasoning about energy: A fourth-grade case study. Journal of Research in Science Teaching. https://doi.org/10.1002/tea.21445. 
Tobin, R. G., Lacy, S. J., Crissman, S., Haddad, N., Wentink, O., \& Seeley, L. (2019). Where does energy go when it's "gone"? Promoting understanding of energy dissipation. American Journal of Physics, 87(7), 569-576 https://doi.org/ 10.1119/1.5110707.

Touitou, I., Carswell, K., Krajcik, J. S., Nordine, J., Neumann, K., \& Fortus, D. (2018). A teacher's perspective on teaching energy differently: Transitioning from a forms and transformation approach to a transfer approach. NARST Annual Conference.

Vosniadou, S., \& Skopeliti, I. (2019). Evaluating the effects of analogy enriched text on the learning of science: The importance of learning indexes. Journal of Research in Science Teaching, 56(6), 732-764 https://doi.org/10.1002/tea. 21523.

Wilson, M. (2005). Constructing measures: An item response modeling approach. Mahwah, N.J: Lawrence Erlbaum Associates.

\section{Publisher's Note}

Springer Nature remains neutral with regard to jurisdictional claims in published maps and institutional affiliations.

\section{Submit your manuscript to a SpringerOpen ${ }^{\odot}$ journal and benefit from:}

- Convenient online submission

- Rigorous peer review

- Open access: articles freely available online

- High visibility within the field

- Retaining the copyright to your article

Submit your next manuscript at $\boldsymbol{\nabla}$ springeropen.com 